Article

\title{
Visualizing the Impacts of Movement Infrastructures on Social Inclusion: Graph-Based Methods for Observing Community Formations in Contrasting Geographic Contexts
}

\author{
Jamie O’Brien *, Laura García Vélez and Martin Zaltz Austwick \\ The Bartlett Centre for Advanced Spatial Analysis, University College London, London, W1T 4TJ, UK; \\ E-Mails: jamie.o'brien@ucl.ac.uk (J.O.B.), laura.garcia.velez@ucl.ac.uk (L.G.V.), m.austwick@ucl.ac.uk (M.Z.A.) \\ * Corresponding author
}

Submitted: 12 July 2017 | Accepted: 21 September 2017 | Published: 28 December 2017

\begin{abstract}
In this article we describe some innovative methods for observing the possible impacts of roads, junctions and pathways (movement infrastructures), on community life in terms of their affordances and hindrances for social connectivity. In seeking to observe these impacts, we combined a range of visualization research methods, based on qualitative points-data mapping, graphic representation and urban morphological analysis at local and global geographic scales. Our overall aim in this study was to develop exploratory methods for combining and visualizing various kinds of data that relate to urban community formations in contrasting urban contexts. We focused our enquiry on the perspectives of adolescents in two urban contexts: Liverpool, UK, and Medellín, Colombia. While they contrast in their geo-political and cultural characteristics, these two cities each present polarized socio-economic inequalities across distinctive spatial patterns. We found that adolescents in these cities offer generally localized, pedestrian perspectives of their local areas, and unique insights into the opportunities and challenges for place-making in their local community spaces. We gathered the communities' local perspectives through map-making workshops, in which participants used given iconographic symbols to select and weight the social and structural assets that they deemed to be significant features of their community spaces. We then sampled and visualized these selective points data to observe ways in which local community assets relate to infrastructural affordances for movement (in terms of network integration). This analysis was based on the theory and method of Space Syntax, which provides a model of affordances for movement across the urban network over various scales of network configuration. In particular, we sought to determine how city-scale movement infrastructures interact with local-scale infrastructures, and to develop methods for observing ways in which these interactions have positive or negative consequences for community formations.
\end{abstract}

\section{Keywords}

movement infrastructures; participatory methods; urban morphology; Space Syntax; visualization research methods

Issue

This article is part of the issue "Regional and Urban Mobility: Contribution to Social Inclusion", edited by Janet Stanley (University of Melbourne, Australia) and John Stanley (University of Sydney, Australia).

(C) 2017 by the authors; licensee Cogitatio (Lisbon, Portugal). This article is licensed under a Creative Commons Attribution 4.0 International License (CC BY).

\section{Introduction}

Urban communities take shape in specific spatial contexts, involving complicated interplays of relationships among people and things in the urban environment (Gans, 2002, 2006; Logan, 2012). On an everyday level, people shape their urban environments by way of structural and social assets such as roads, open spaces and landmarks. The movement infrastructures that connect people and environments include roads, street networks, pathways and junctions across local, urban and regional scales (Batty, 2013; Hillier \& Vaughan, 2007; Sampson, 
Morenoff, \& Gannon-Rowley, 2002; Urry, 2002). These scales of movement overlap along street segments, which we see when city-wide traffic convergences on local spaces. In some contexts, this overlapping helps people connect to the city network, and in other contexts it gets in the way of community life. For this reason, the social and structural assets from which urban communities are formed are inter-dependent with situated, contextual urban forms (Debertin \& Goetz, 2013; Gwyther, 2005; Hillier \& Hanson, 1984).

Individuals and social groups often use the intelligible properties of assets to navigate their way or achieve their sense of place. For this reason, movement infrastructures are relational to communities' needs within the urban environment, forming boundaries, thresholds and interfaces, with the potential to divide, connect and allow interaction (Palaiologou \& Vaughan, 2012). Given the relational complexity of these infrastructures, the specific ways in which they impact on community life (both positively and negatively) are often overlooked by urban professionals. For example, ostensibly 'trivial' streets actually serve as significant inter-connections among community groups (Grannis, 1998, 2009), and occasional places for stopping, chatting or playing become important anchors for community life (Power, 2007, pp. 58-59).

In this article we seek to observe how city-scale infrastructure impact on community formations at the local scale. Movement infrastructures can also 'severe' communities through a 'chain of effects' relating to physical barriers and cognitive stress (Anciaes, Boniface, Dhanani, Mindell, \& Groce, 2016), bearing both conceptual and physical properties (Hillier, 2007, pp.67-68; O'Brien \& Psarra, 2015). These can relate to perceived boundaries that enforce stereotypes of 'us' and 'them' in the urban landscape (Sibley, 1995). Even within homogenous urban contexts, this sense of place is not fixed, but varies according to, for example, a person's age, gender, level of ability, socio-economic standing or stage in life (Lupton, 2003). For example, intensively normative, class- and place-bound community formations have been observed among adolescents (Hanley, 2017; McKenzie, 2015).

In our recent research at University College London, we sought to address some methodological challenges in understanding the 'relational complexity' of urban community spaces. We focused on the experiences of community formations in contrasting urban spatial contexts among groups of 11-19 year-olds. We focused on these groups primarily because their views are often not included in formal urban planning processes (cf., UNESCO, 2002). However, their experience of urban spaces is likely to combine notions of 'rational choices' (for example, their friendships), with those of imposed rules (for example, their obligation to attend school). As such, this group would not fit some standard socio-economic methodologies for understanding urban community formations (Miller, 1992). For this reason, our research focused on the methodological challenges of observing urban community formations among young people, combing morphological, demographic and qualitative data.

We have configured some innovative visualization methods from which to observe community formations and their urban contexts, which we outline below. The participatory section of the research revealed that movement infrastructures feature as one type of asset among many others within the sampled community formations, across all age groups and socio-economic contexts. Other dominant features included open spaces, such as public parks and leisure facilities, shopping areas, industry and sites of pollution, and local schools. We focus the present analysis and discussion on what these methods might show about impact of movement infrastructures (roads, streets, junctions and pathways).

\section{Methods}

The aims of the research posed a methodological challenge in bringing together an understanding of community perceptions of their local spaces and the spatial dynamics of the wider urban network. We addressed this challenge by gathering community perspectives through participatory workshops (described in detail in O'Brien et al., 2016), and by using Space Syntax as a theory and method of urban morphological configuration, based on the notion of affordances for 'natural' movements across street networks. These affordances are termed 'movement potentials' within the Space Syntax literature (Hillier \& Hanson, 1984; Hillier \& lida, 2005). The scripts generated to display the findings of the workshops and applied network models, as described throughout this article, can be freely accessed via an online repository. ${ }^{1}$

\subsection{Areas of Study}

Our aim in this section of our research was to compare community formations in contrasting contexts. We selected field sites in Liverpool, UK, and Medellín, Colombia, which offered opportunities to address comparative experiences of community formations in transforming urban environments. The sites' widely different geographic and cultural environments provide contrasting contexts to our study (Robinson, 2016). Each city is a non-capital, medium-sized conurbation, presenting morphological characteristics of grid-pattern, inner suburban street networks and low-density peripheries. In stark contrast to Liverpool, Medellín is situated inland, bearing peripheral topographic elevation with widespread unplanned settlements. Each city also bears radial road networks that have formed around riverside settlements, and have shaped the overall spatial dynamic in both instances (cf., O'Brien \& Griffiths, 2017).

Liverpool is the UK's third city by regional population. While enjoying higher than-average economic growth in the period 2009-2014 (Liverpool City Council [LCC],

$\overline{1}$ https://github.com/laligave/Visualizing-Community-Inequalities 
2016a), the city has among the highest levels of multiple deprivations of any UK local authority (LCC, 2015). The Liverpool region is 'a place of contrast and social and spatial disparities' (Sykes, Brown, Cocks, Shaw, \& Couch, 2013), bearing a range of spatial inequalities reflected in zonal concentrations of wealth and poverty (Sykes et al., 2013, p. 6). The city region can be characterized historically as an area of prolonged industrial decline, reflected in higher-than-average unemployment (currently $5.1 \%$ ) neighbourhood dereliction (Leeming, 2013), and low business density (LCC, 2013). There are signs of economic renewal in the region: the Mersey estuary region is now attracting massive brownfield infrastructural investments, with groundwork currently under way.

Medellín is the second city of Colombia, a country that experiences among the highest levels of socio economic inequalities in Latin America. Medellín has been characterized historically by high levels of deprivation, serious crime and social isolation (Hylton, 2007). The city has, in recent years sought to overcome sociospatial and economic inequalities through several infrastructural initiatives. These include a peripheral transport network, cable car system and an outdoor escalator that helps to integrate the deprived hillside neighbourhood of Comuna 13 (cf., Brand \& Dávila, 2011; Drummond, Dizgun, \& Keeling, 2012). While levels of multidimensional poverty in the city have lowered overall in recent years (Medellín Cómo Vamos [MCV], 2016a), rising living costs have led to an increase in reported experiences of poverty in the city's poorer neighbourhoods (MCV, 2016b).

To observe aspects of urban community formations within these urban contexts, we selected areas to represent a range of socio-economic contexts. Figure 1, below, shows the areas where the map-making workshops were conducted in Liverpool. These workshops were undertaken at schools within zones presenting a range Index of Multiple Deprivation (IMD) scores (DCLG, 2015). These statistics are organized by Lower Super Output Areas (LSOAs) that represent surveys of approximately 8003000 people (a detailed description of the selection is provided in O'Brien et al., 2016). These provide measures of relative deprivation in the surroundings of each school. Note, for example in the figure, how the North Liverpool Academy community coincides with moderate to high multiple deprivations, while the Blue Coat Community coincides with moderate to low multiple deprivations.

In total, 246 participants engaged in the workshops, including $34 \%$ male and $66 \%$ female students. The total number and gender distribution of the surveyed students are also depicted in the pie charts of the Figure 1. Note a bias in the sampling towards female participants, which was the result of voluntary engagement with the project and not of deliberate sampling.

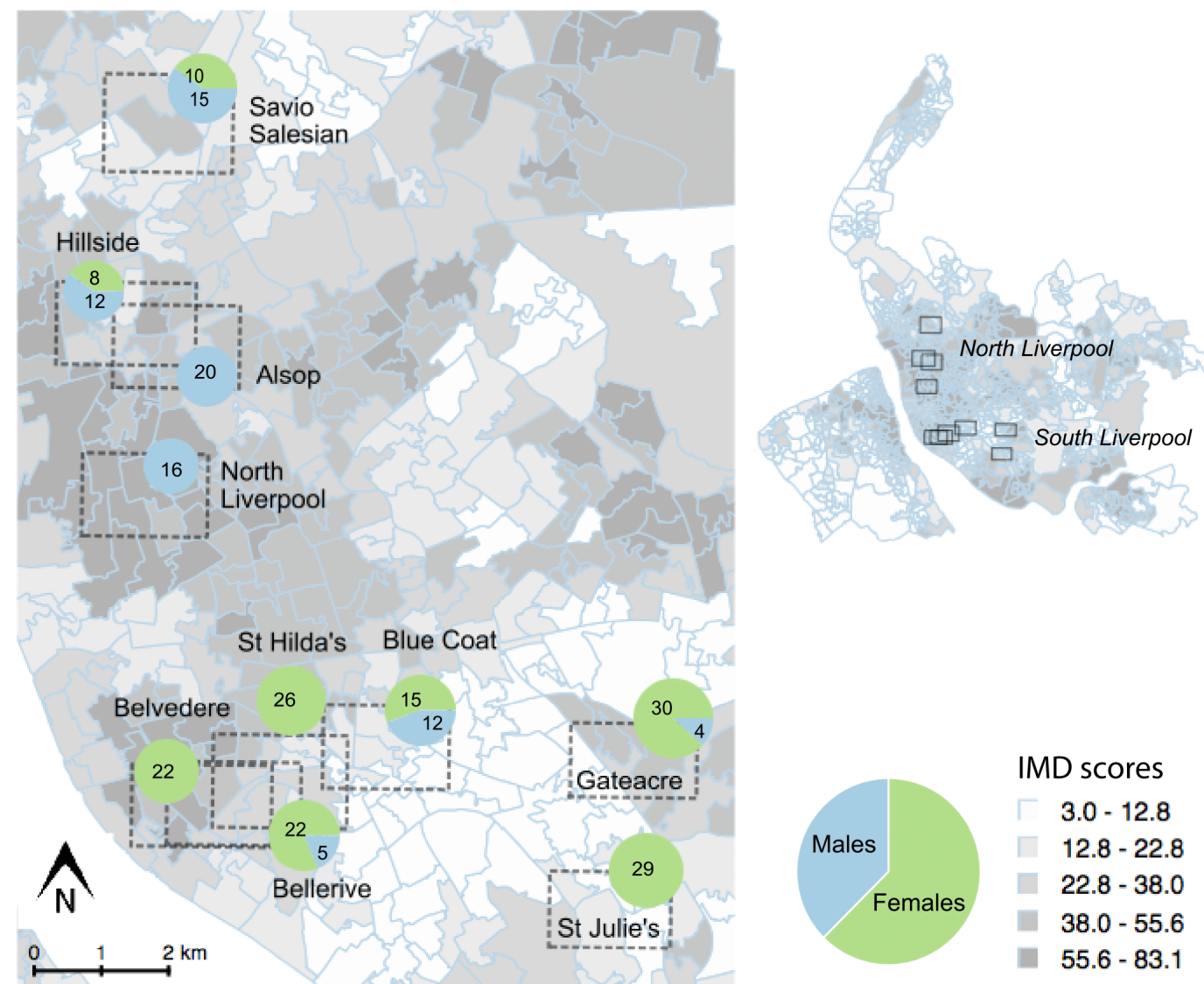

Figure 1. Locations of communities sampled over socio-economic status in Liverpool, UK (based on IMD; low-to-high values shown on a dark-to-light ramp). Pie graphs displaying number and distribution of participants in each workshop site. 
In the case of Medellín, shown in Figure 2, the areas of study were located in the local government districts (or comunas) of Belén and San Javier. The neighbourhoods within each comuna appear classified according to an index derived from the elective Sistema de Identificación de Potenciales Beneficiarios de Programas Sociales (SISBEN surveys, 2015), which measures relative vulnerability with respect to quality of life (See Appendix for more details). Overall, it is possible to observe in Figure 2 that the neighbourhoods with higher relative vulnerability according to the SISBEN index are located in the north and west peripheries of the city. From the districts of study, the neighbours of Belén are more heterogeneous in terms of relative vulnerability.

During the workshops, the participants worked first on maps of the complete district, but also on maps of specific groups of neighbourhoods within each comuna (see 5 and 3 subareas for Belén and San Javier, respectively). In total, 170 participants engaged in the activity, including $48 \%$ male and $52 \%$ female students. The pie charts in the Figure 2 display the disaggregation of the participants in each subdivision. Note, for example, that the subarea 1 of San Javier has the highest number of surveyed students, which was the result of the selection that each participant made to work on a specific subarea.

\subsection{Community Workshops}

In gathering data pertaining to the community perspective, we adapted the ethnographically based approach of Rural Community Appraisal, which helps to equip participants in analysing and describing their own 'realities' (Chambers, 1997). To achieve this, we invited participation among 11-19 year-olds through the cooperation of secondary schools in Liverpool and the Parques Biblioteca in Medellín, which are a system of libraries that offer cultural programmes for the local schools. We devised and ran a series of workshops, located at school facilities in Liverpool and library facilities in Medellín. The workshops engaged the participants in brief introductions to urban planning and design using city-scale maps, which helped their understanding of how interventions impact on community life. As most participants were children, it was not possible to gather data about individual circumstances. However, an assumption was made that the participants had general experience of typical social, structural and environmental characteristics of their local areas.

In Liverpool, the participants worked with local-scale maps, in which the cartography located the workshop site at the centre of an approximately $2 \mathrm{~km}^{2}$ area. Partici-

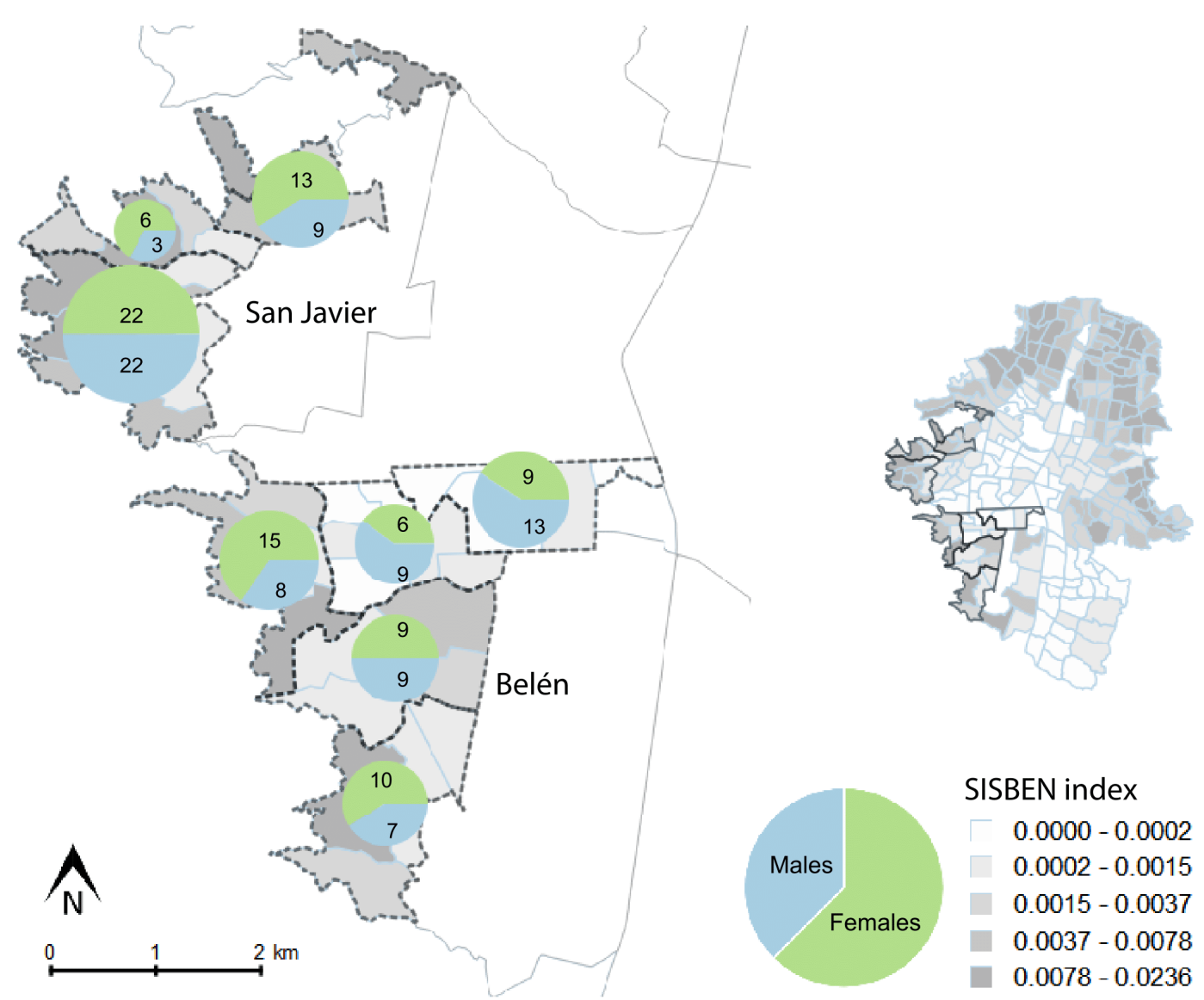

Figure 2. Locations of communities sampled over socio-economic status in Medellín, Colombia (based on an index derived from SISBEN surveys; low-to-high values shown on a dark-to-light ramp). Pie graphs displaying number and distribution of participants in each workshop site. 
pants used well-known 'emoticon' symbols (Figure 3), to associate basic emotions and experiences in specific urban environments. The participants were free to represent and locate using the provided symbols (see further details in O'Brien et al., 2016).

For the Medellín case, the provided iconographic stickers are illustrated in Figure 4. An early consultation with community organizers prompted the investigators to offer site-specific icons to enrich the descriptions associated to the features with positive and negative connotations. Specifically, symbols to represent problems with rubbish, pollution, physical boundaries, as well as different experiences at day and night. These symbols were used by the participants to select the features of their local areas with positive and negative connotation, including those within the comuna and the subarea that each participant selected.

Following the selection of the features of the local areas that deemed significant for community formations in both case studies, all participants were invited to fill out a table to list and describe the emoticons and icons they used on their maps. For example, a 'shocked face' emoticon relating to a major junction was described as 'Can't get across, too much traffic!'. This allowed the investigators to identify structures or places in terms of their affordances and hindrances for social connectivity.

Finally, all the maps were scanned into a GIS and points-data were digitalized and tabulated by gender, age-group, urban type ('road', 'open space', and so on), the specific name of the selection, and any text descrip- tion were this was available. All data were aggregated to reveal distributions of icon weights and grouped based on their 'positive' or 'negative' connotations, so as to guarantee consistency on the comparison of the case studies. Further research will be conducted to document the specific interpretations realized by the participants in both case studies.

\subsection{Urban Morphological Analysis}

In order to model the possible impacts of movement infrastructures, the investigators generated a series of morphological models using Space Syntax. Space Syntax is a theory and method that describes the relationship between the configuration of the built environment and people's natural movement around urban forms. The model is based on measurements of distances among network segments, weighted by the depths of angles between segment intersections (the shallower the angle for turning from one street segment to another, the higher the natural movement). Space Syntax's core technology, the Depthmap software application, ${ }^{2}$ provides a visual model of any sampled urban street network (or architectural space). The application typically uses a warmto-cool colour ramp to represent high-to-low values for movement potentials across the network. Depthmap handles two bespoke calculations. 'Choice' represents the probable affordances for movements 'through' the network. 'Integration' represents affordances for 'origin/destination' movements. A useful example of Space

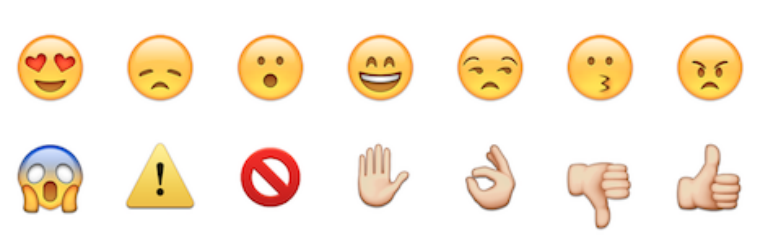

Figure 3. Emoticon stickers used in the Liverpool map-making workshops.

Positive connotation

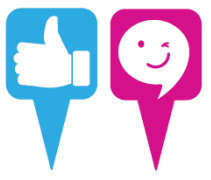

Negative connotation

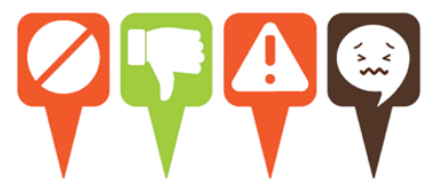

Descriptions

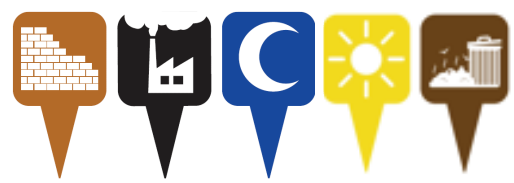

Figure 4. Iconographic stickers used in the Medellín workshops.

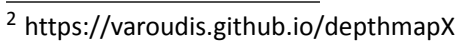


Syntax in practice is in the representation of a city's Integration core, which shows its overall 'centre of gravity' in terms of movements. We provide case study examples of these in Figures 5 and 6. Low-to-high values are shown on a cold-to-hot ramp, which represent the quintiles were the integration value of each street segment falls.
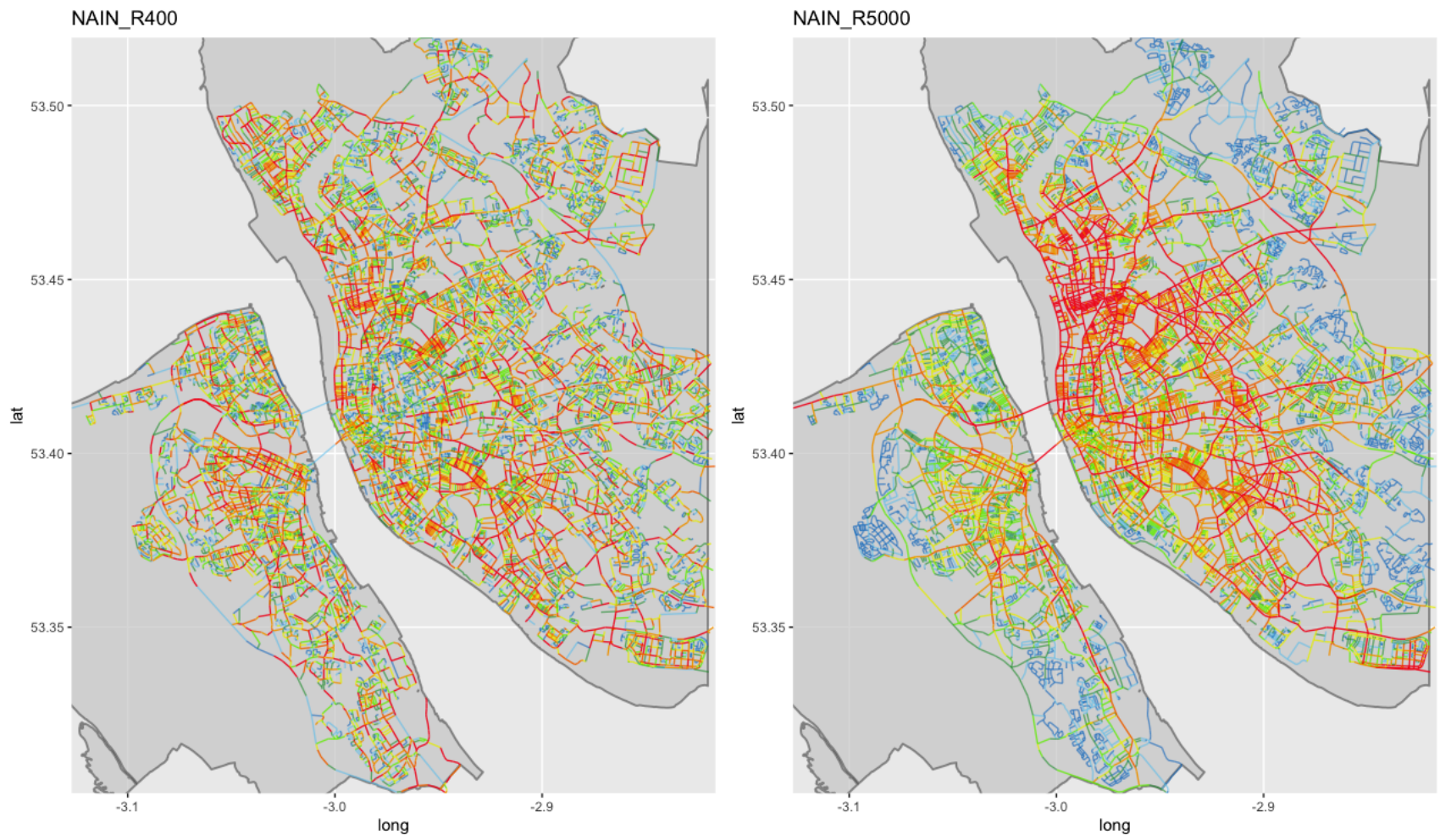

Figure 5. Urban Integration cores for the Liverpool, UK, conurbation. Left: local scale based on 400m; Right: global scale based on $5000 \mathrm{~m}$.
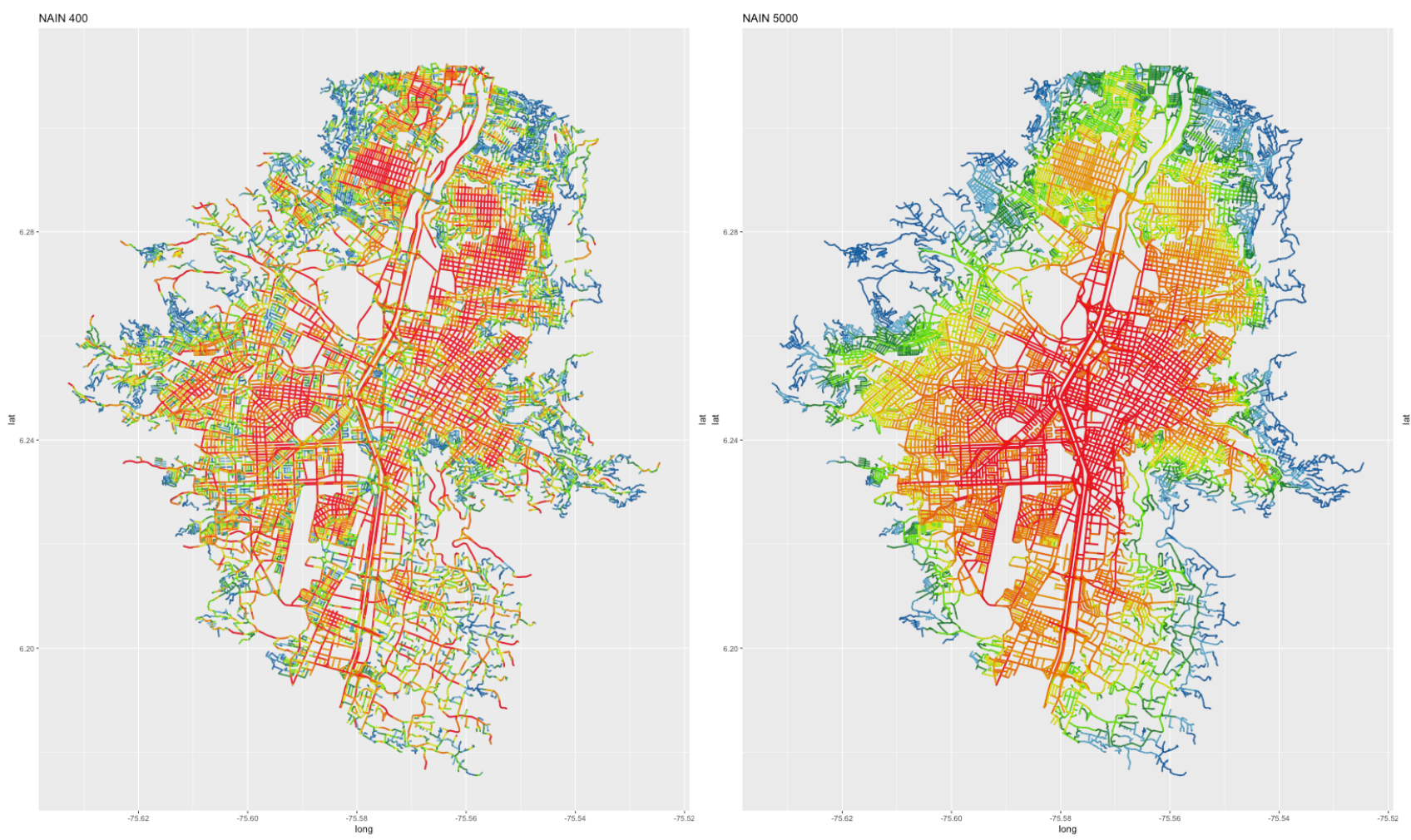

Figure 6. Urban Integration cores for Medellín, Colombia. Follows the format for Figure 5. 


\section{Results}

\subsection{Relevant Places Selected by Community}

We sought to observe how the features selected by the participants were related in space based on the community perspective. We applied K-nearest neighbor graphs to the data, where the nodes represent the selected local features and the edges the four closest neighbors (see Figures 7-8 and 12-13). The graph nodes are geo-located based on the centroids for each cluster of iconographic symbols arranged by name (for example, the centroids for all points with name 'Princes Park'). The node sizes were adjusted in proportion to the count of icons applied to each feature (\%). The Euclidean (shortest path) graph edges represent the 'semantic' distances among the features selected. For example, participants at Bellerive and St Hilda's have attached high significance to local open spaces (coloured yellow; in the Figure 7 they are 1. Sefton Park and 2. Princes Park). Alsop and Hillside have attached greater significance to nearby movement infrastructures (coloured red; 3. County Road and 4. Breeze Hill Roundabout) which in each case seem to mark a functional separation among groups of features within the community's local space. The k-nearest graphs, including all the legends for the local features can be further consulted in the following hyperlink: Liverpool. ${ }^{3}$
In the case of Medellín, it stands out that participants attached high significance to recreational and commercial areas (coloured light and opaque green in Figure 8-left; 1 . Sports Centre UD de Belén in the subarea 1, and 2. Shopping Centre CC Molinos in the subarea 2). Participants attached medium significance to nearby water courses in the majority of subareas (coloured red in Figure 8; 3-6 for Belén, and 2-4 for San Javier), which were also defined as spaces associated with contamination and or the sense of insecurity. On the other hand, other elements affording movement as the electric stairs in San Javier (coloured red; 1 in Figure 8-right), are associated mostly with positive connotations and therefore features that afford community integration. In comparison to the local features mentioned above, the streets have relative lower significance (coloured red in Figure 8; 7-12 for Belén, and 5 for San Javier). The k-nearest graphs, including all the legends for the local features can be further consulted in the following interactive links: Belén ${ }^{4}$ and San Javier. ${ }^{5}$

\subsection{Urban Morphological Analysis}

From the Knn graphs, we were able to see how some major roads played a role in community formations. In the next stage of the research, we sought to understand how these roads are configured within the local community

\section{North Liverpool}

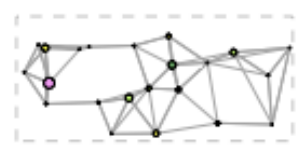

\section{South Liverpool}
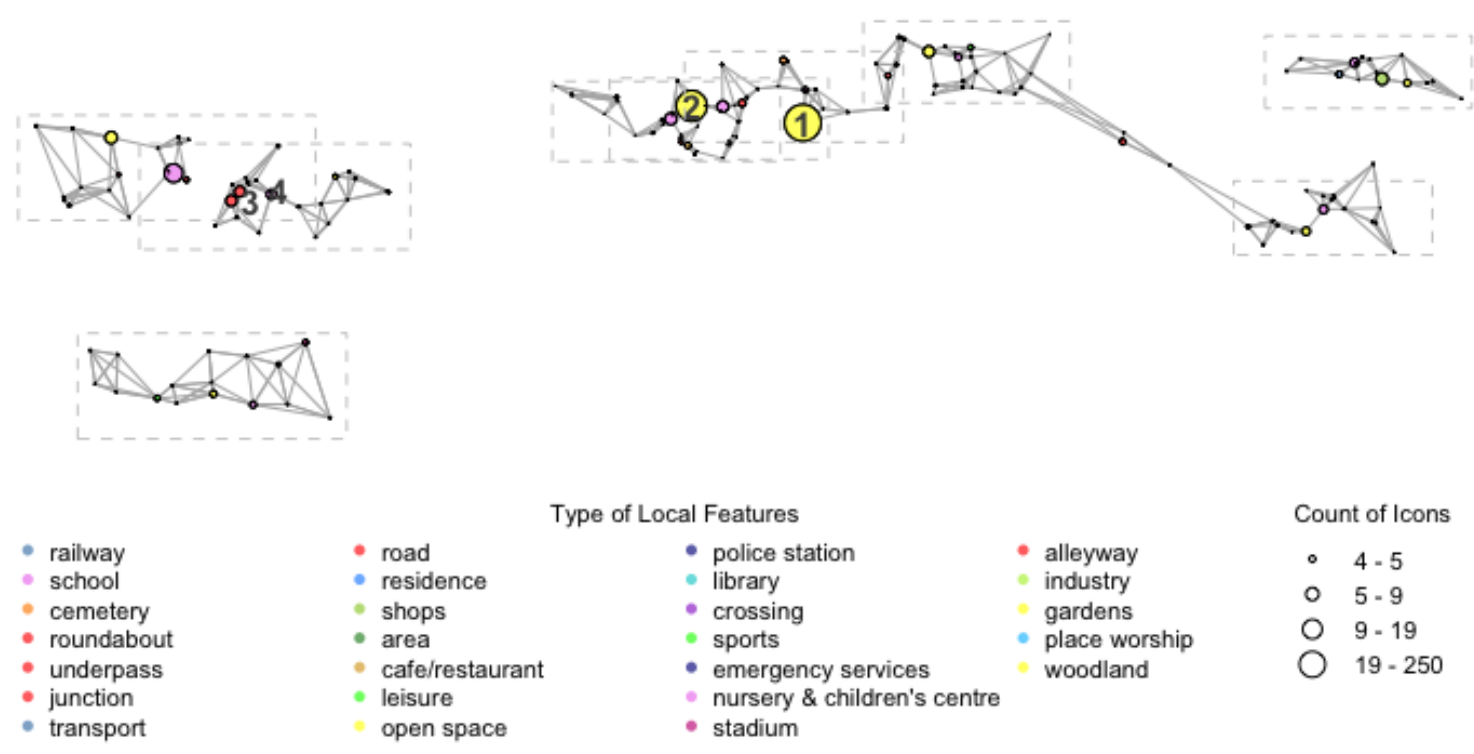

Princes Park

3 County Road

4 Breeze Hill

Figure 7. K-nearest neighbour graphs of the Liverpool group of sampled communities.

\footnotetext{
3 Interactive web graph (Liverpool) available via: http://tinyurl.com/y93jhwvw

${ }^{4}$ Interactive web graph (Belén) available via: http://tinyurl.com/y9ycmhlt

${ }^{5}$ Interactive web graph (San Javier) available via: http://tinyurl.com/yb47js28
} 


\section{Belén}

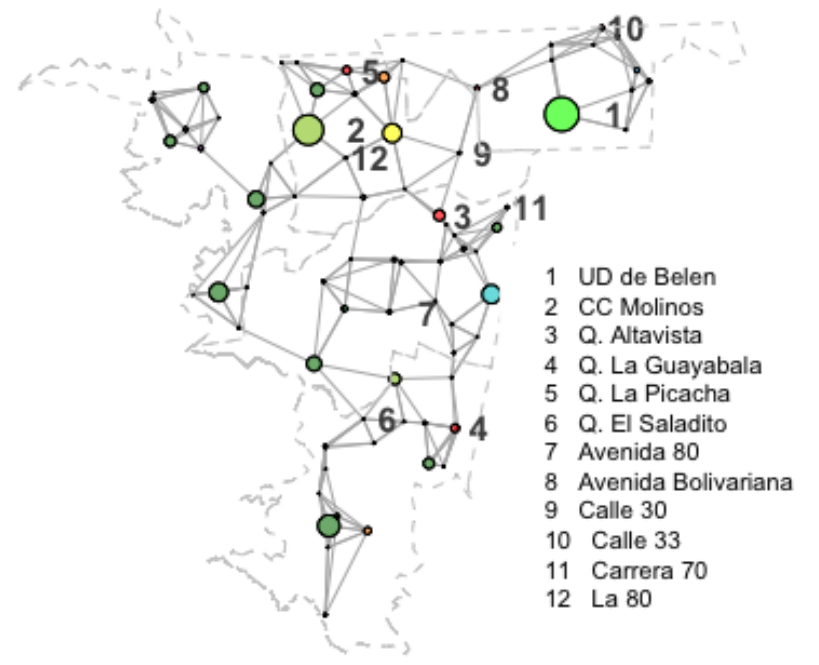

\section{San Javier}

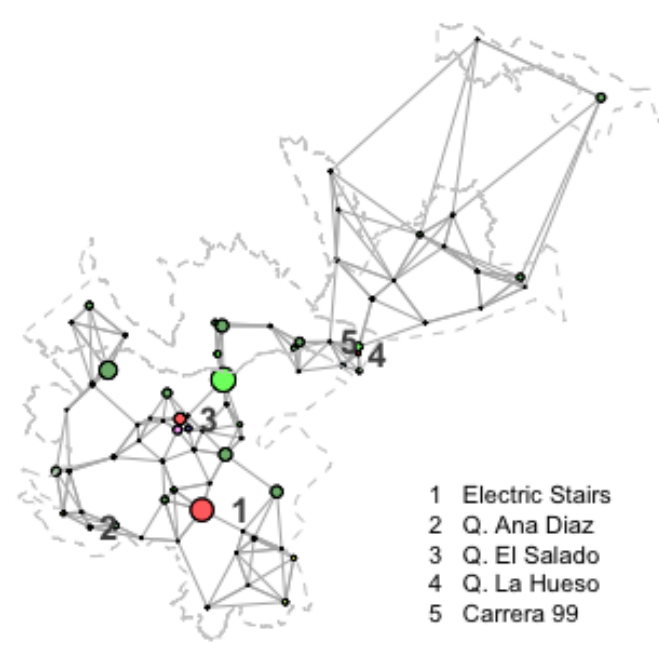

\begin{tabular}{|c|c|c|c|c|c|c|}
\hline \multicolumn{6}{|c|}{ Type of Local Features } & Count of Icons \\
\hline - Airport & Green Area & - Metro & - Street & - Stream & - Water Tank & - 4-6 \\
\hline - Bus Terminal & - Government & - Neighborhood & - Sports Centre & Energy & & $6-11$ \\
\hline - Cemetery & - Hospital & Perifery & Shopping & - Fireman & & $11-24$ \\
\hline $\begin{array}{l}\text { - Cultural } \\
\text { - Club }\end{array}$ & $\begin{array}{l}\text { Industry } \\
\text { Landfill }\end{array}$ & $\begin{array}{l}\text { Quarry } \\
\text { Residential }\end{array}$ & $\begin{array}{l}\text { - School } \\
\text { - Supermarket }\end{array}$ & $\begin{array}{l}\text { - Police } \\
\text { - Pedestrian }\end{array}$ & & $24-108$ \\
\hline - Church & - Library & - Round Point & Square & - Recreational & & \\
\hline
\end{tabular}

Figure 8. K-nearest neighbour graphs of the Medellín group of sampled communities.

space, including their interactions with the city network. This involved analysis of urban morphological integration at local and city scales based on the Depthmap measurement of Normalised Integration (NAIN). To reiterate, the Integration model demonstrates the likelihood of network segments affording origin-to-destination movements within a certain radius of network configuration.
NAIN can be seen as providing a model of spatial accessibility within the network.

We generated urban morphological models based on Integration at radius $400 \mathrm{~m}, 2000 \mathrm{~m}, 5000 \mathrm{~m}$ and global scale (which were then normalized for comparison; see the examples in Figures 9 and 10 for Liverpool and Medellín, respectively). We then extracted the range
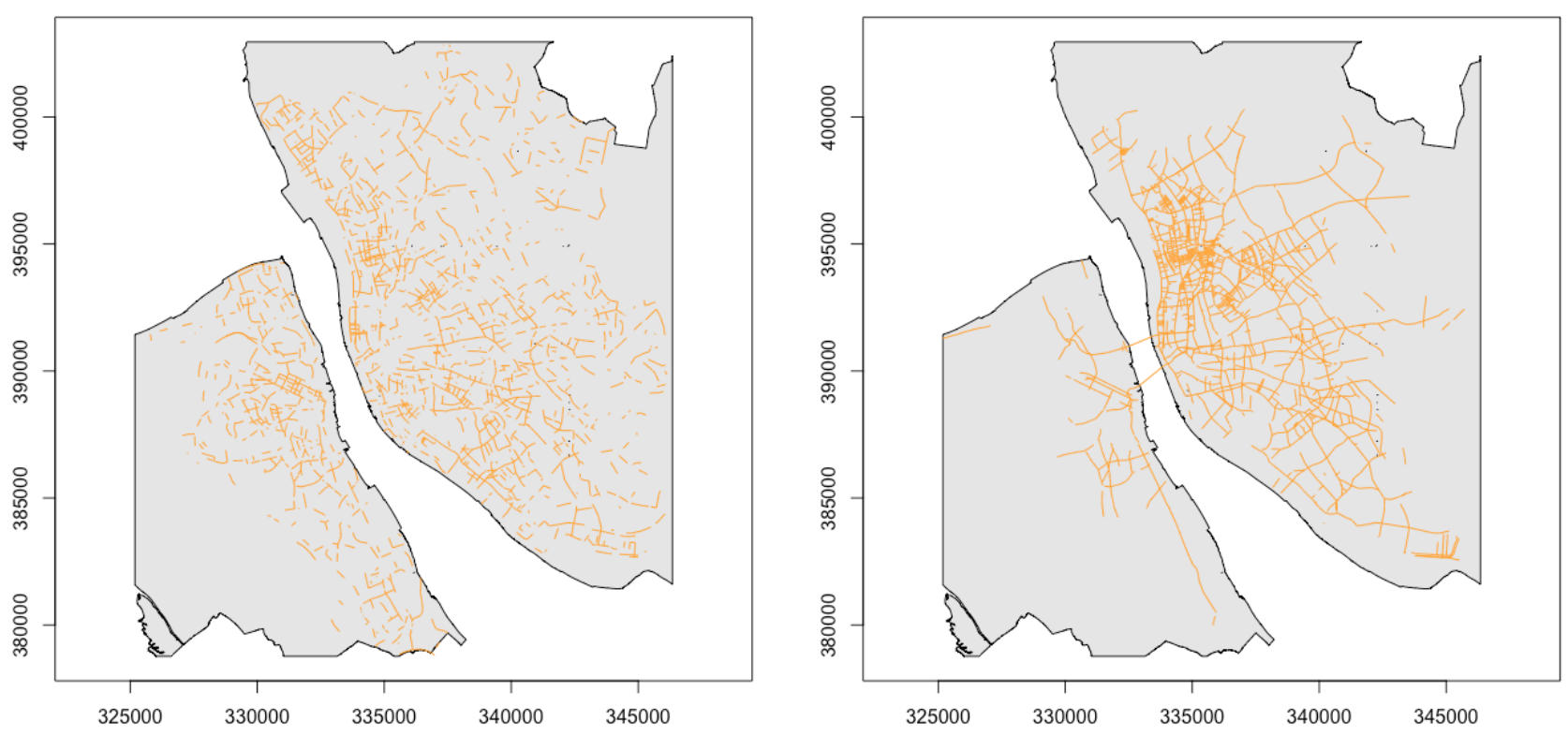

Figure 9. Urban morphological models for Liverpool based on Integration at scales of local (left) and global (right) radii. The maps represent the highest affordances for origin-to-destination movements at these scales (based on the top 20\% Integration value range). 

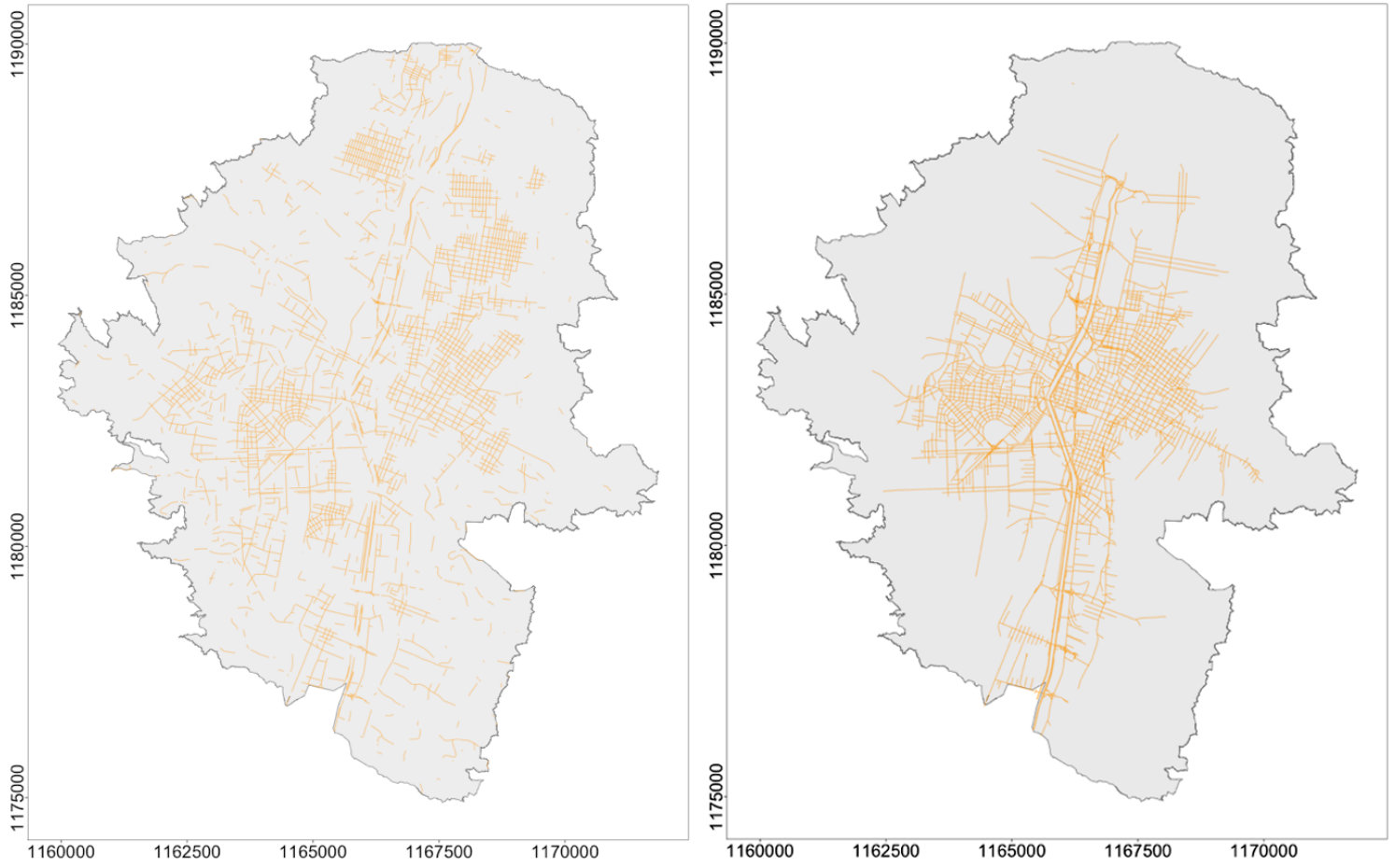

Figure 10. Urban morphological models for Medellín. Formats are as Figure 9.

of network sections at which high-value local segments $(400 \mathrm{~m})$ overlap with high-value global-scale segments (Figure 11). The purpose of this was to observe the 'potential' impacts of wider-scale movements on localscale centralities.

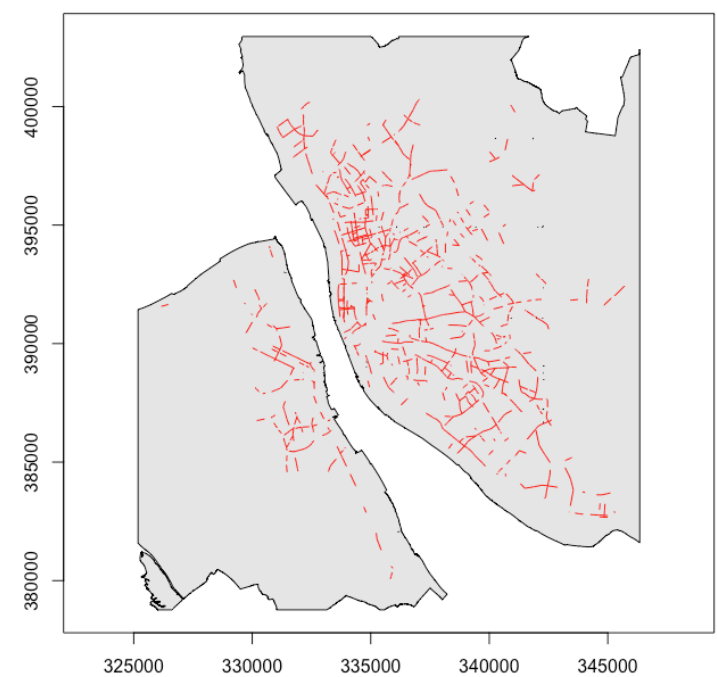

Medellín (right).

\subsection{Impacts of Local and Global Movement Infrastructures on Community Formations}

The arrays of community sample maps for (Figures 12 and 13 ) reveal how icons with 'positive' (orange) and

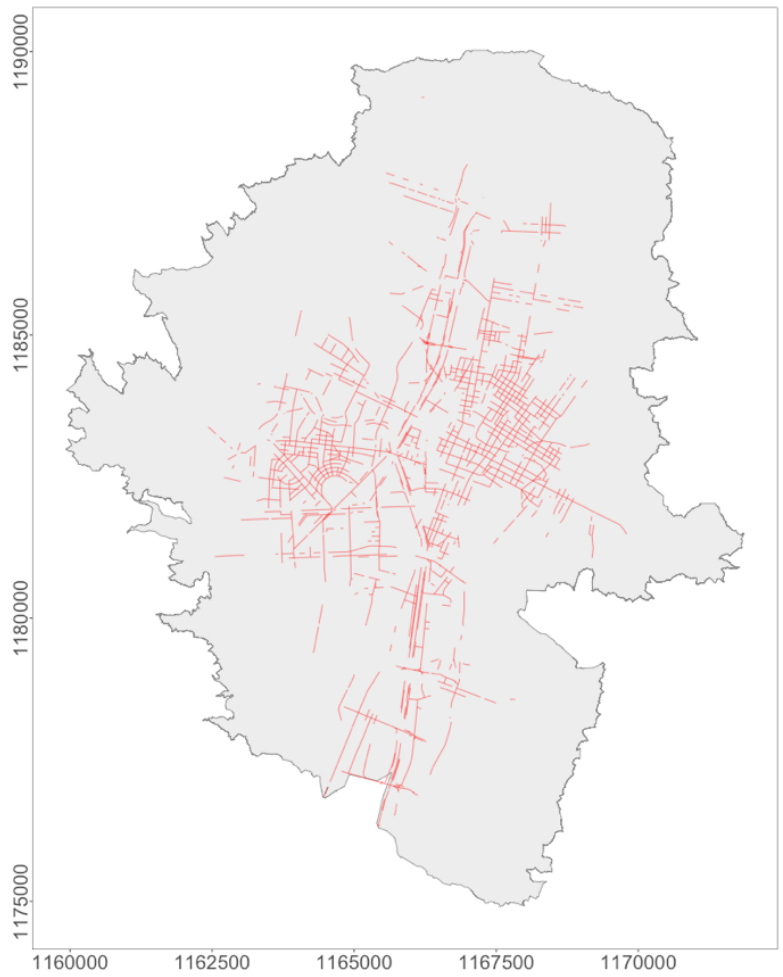


'negative' (blue) connotations where applied to movement infrastructures. Communities that share network spaces (such as Bellerive, Belvedere and St. Hilda's, and also Hillside and Alsop in Liverpool, and most of the samples communities in Medellín), present very similar impressions of their local spaces, with each community applying similar weightings to major local infrastuctures, such as busy roads, junctions and pathways running by water courses for the Medellín case. The weights applied to these movement infrastructures where based mainly on negative representations (of 'shock' or 'sad', and so on).

Perhaps surprisingly, the majority of icon weights were applied to movement infrastructures that do not tend to converge NAIN local and global scales. We might hypothesise that the communities' respective 'sense of place' (whether based on negative or positive connotations), is affected by movement potentials bearing singular, dominant NAIN-scale segments. We can look at this pattern in different ways. One possible interpretation is that movement infrastructures that converge NAIN scales repel community life. Another is that the participatory methodology has revealed how 'negative spaces' of community life form around non-convergent movement infrastructures.

\subsection{Observing Movement Potentials in Relation to Socio-Economic Patterning}

Our aim in this section of work was to take a broad survey of the wider urban contexts in which our sample populations were situated. We based this survey on measurements of 'potential' impacts of city-scale centralities on local centralities, in relation to spatial distributions of relative deprivations. We sought to understand how overlaps among local and global NAIN scales might relate to distributions of relative deprivations or vulnerabilities. We addressed this based on IMD ranges (DCLG, 2015) for Liverpool, and the elective SISBEN surveys (2015) for Medellín. See details in the Methods Section and Appendix.

In detail, we measured the total length of segments that feature overlapping movement potentials within square subdivisions ( $40 \times 40$ grid), as a percentage ratio of the total length of all segments in each square. This allowed us to measure the degree to which movement infrastructures in a local area interacted across radial distance scales. For example, certain areas might feature high-density street networks, but have few segments interacting with city-scale movements.

The Figure 12, below, shows for Liverpool, the results for the square subdivisions within each Lower Su-
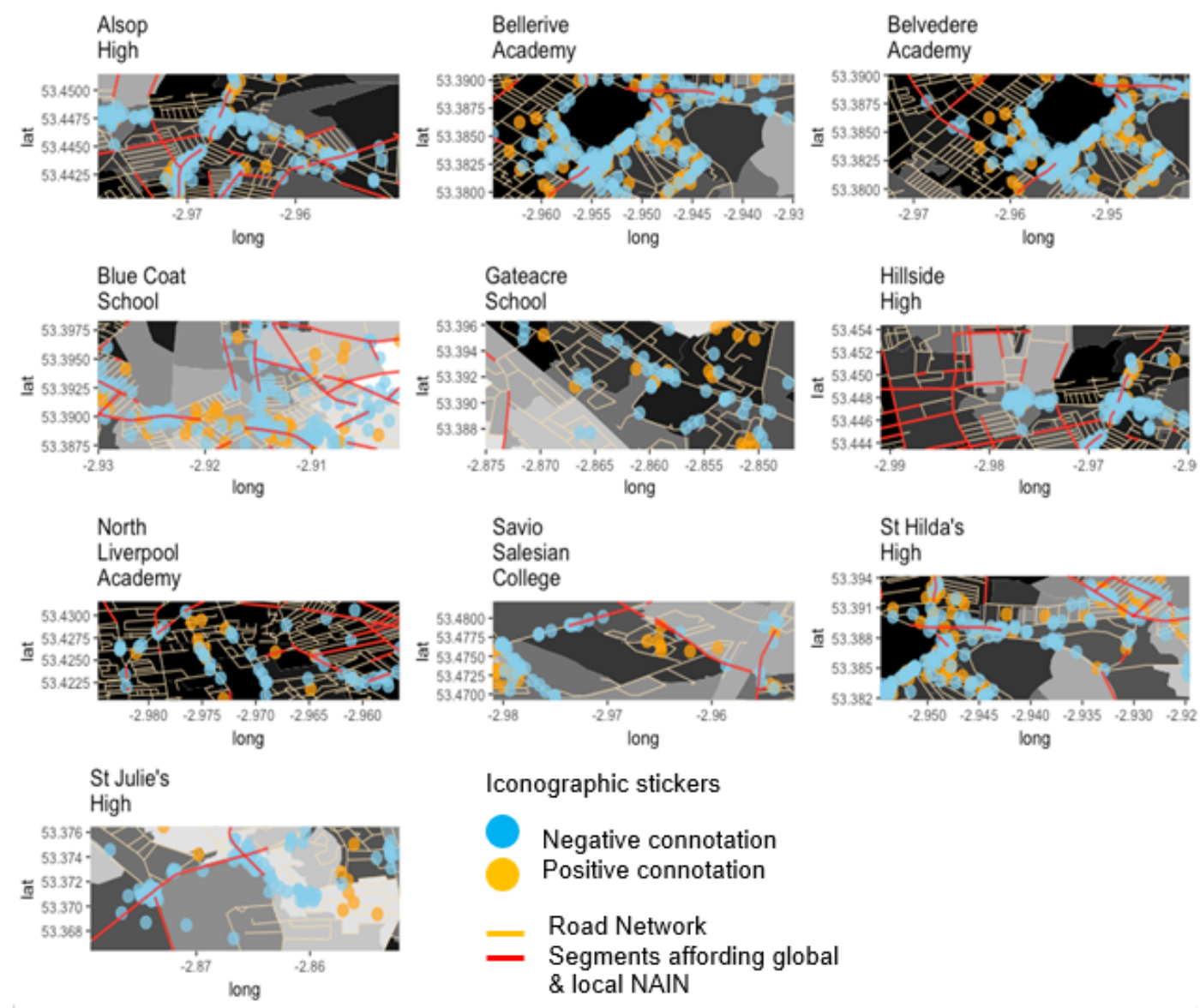

Iconographic stickers

Negative connotation

Positive connotation

Road Network
- Segments affording global
\& local NAIN

Figure 12. Array of community samples showing extract Depthmap segments overlaid on IMD by LSOA (Liverpool case study). Blue points represent negative weights such as 'sad', 'shocked', etc. Orange represents positive weights such as 'love', 'happy' etc. 
per Output Area (LSOA). A choropleth array was generated to represent the segment length counts broken down by IMD score quintiles, which vary across a lowdeprivation to high-deprivation range of 2.96-82. In the figure, the distribution of network interaction lengths is color-coded from light (low length count) to dark (high length count). The Figure 13, shows for Medellín, a similar analysis using the SISBEN score quintiles associated to each neighbourhood.

We then applied this sampling process to additional Depthmap models of Medellín, in relation to spatial distributions of vulnerability. We mapped these distribu-
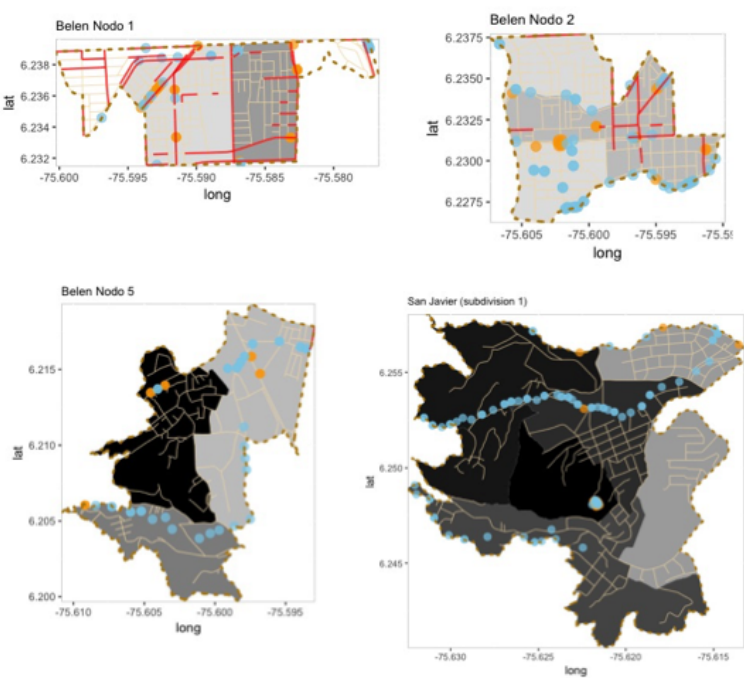
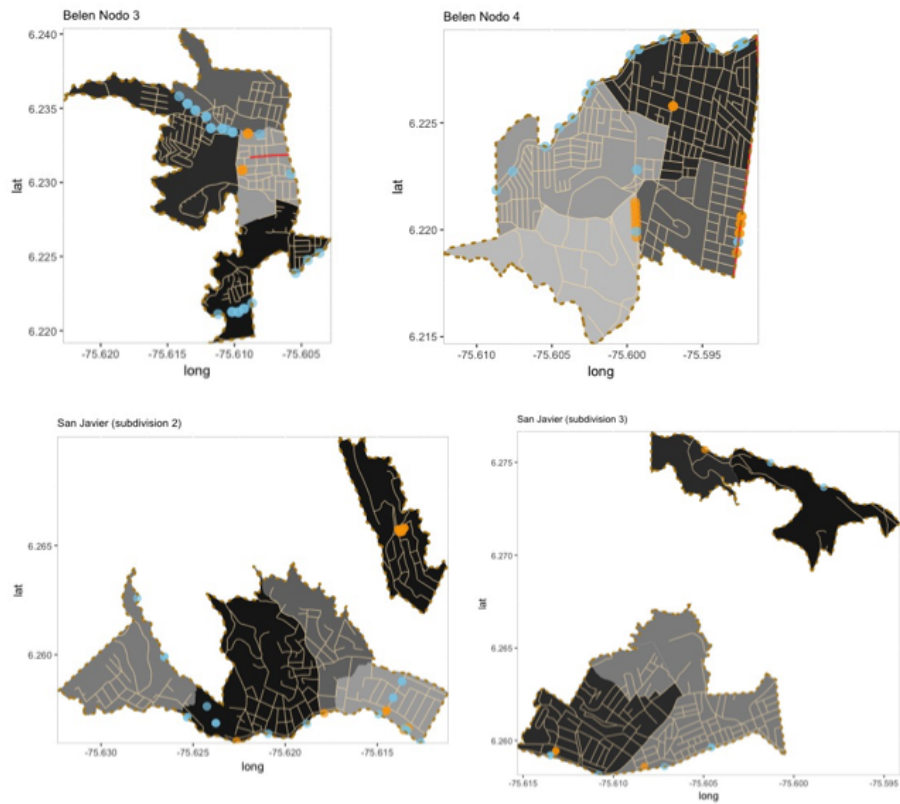

Figure 13. Array of community samples showing network map (Medellín case study). Colour coding as in Figure 9.

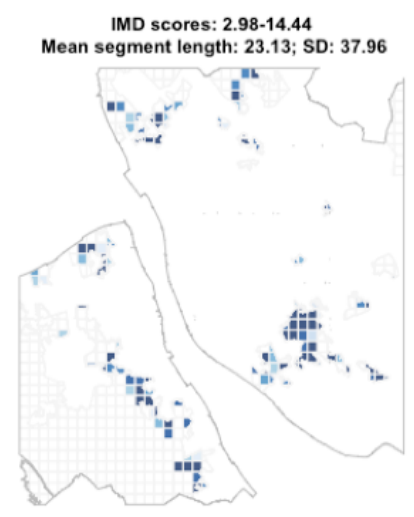

IMD scores: $44.21-58.85$ Mean segment length: $43.83 ; \mathrm{SD}: 41.58$

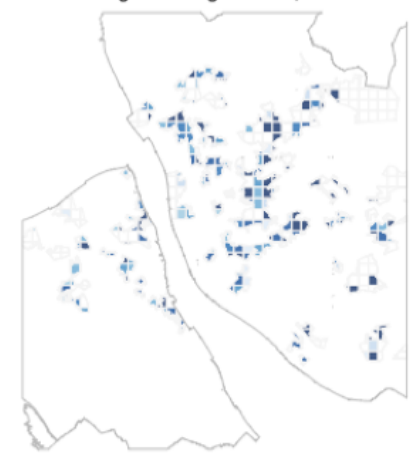

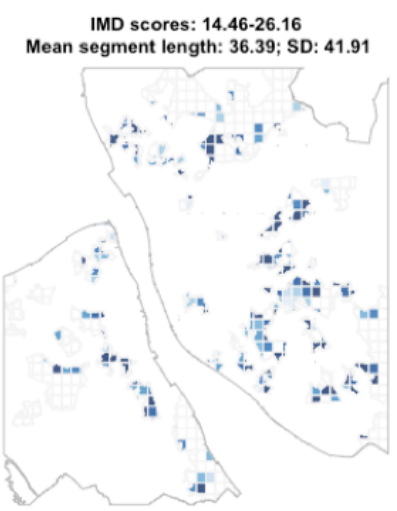

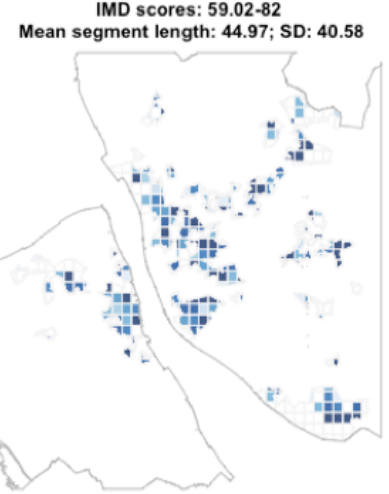

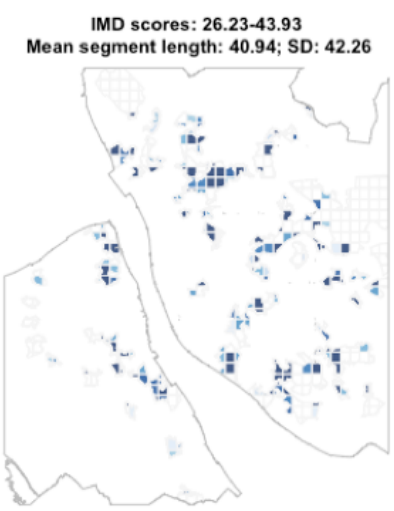

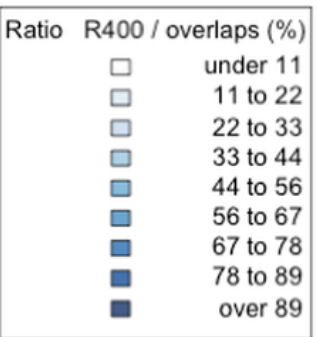

Figure 14. A choropleth array representing total lengths of network segments with 'overlapping' movements in each square subdivision as a ratio (\%) of all network segments in that area. The sampling grid (raster) has been clipped based on IMD score quintile ranges. The plots run high IMD score top left to low IMD score bottom right. 

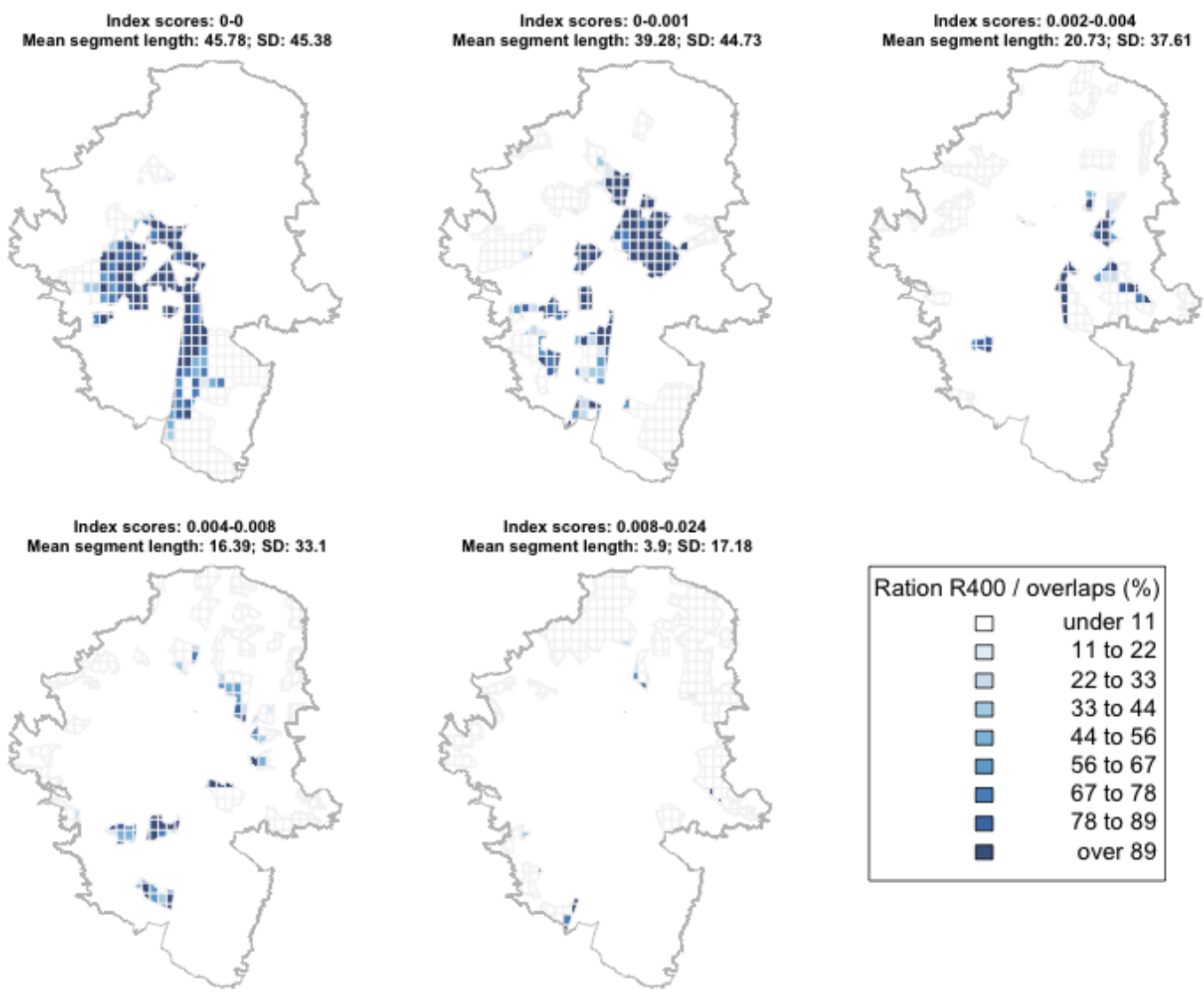

Figure 15. A choropleth array of Medellín based on SISBEN score quintiles, following the same sampling format shown in Figure 12. However, the plots run low vulnerability top left to high vulnerability score bottom right.

tions with the choropleth format described above (see Figure 13). The morphological analysis of interaction among local- and urban-scale centralities in the sample data has revealed the potential impact of wider centralities on local centralities among areas across the range of deprivations or vulnerabilities.

\section{Conclusions}

Our aim has been to develop innovative methods for observing some possible impacts of movement infrastructures in urban community formations. We argued that urban communities make use of artefacts in their local spaces that, by combining physical and relational properties, are relational to the activities and perspectives of the community members. We wanted to observe how the major presence of roads, streets and pathways in community spaces served to shape the 'sense of place' in that area. We drew from three sources of data: geo-located points-data derived from participatory workshops, socio-economic data from public sources, and urban morphological data pertaining to probabilistic urbannetwork interactions.

The study participants were invited to mark on the map what structures in their local areas they considered to help or to hinder processes of social inclusion that underpin community formation. We extracted selections of movement infrastructures (including roads, streets and pathways). We found that the impact of movement infrastructures is far from even, and depends highly on the local community context. Following this observation, we took a wider-scale perspective, and found a more common pattern in the general significance of road segments. Among communities where movement infrastructures are more significant overall, they apply greater significance to structures where scales of movement do not tend to converge (based on Integration, representing affordances for origin/destination movements; where 'significance' was reflected in iconographic weights representing overall negative values). In other words, their 'sense of place' in relation to movement infrastructures forms around structures with low or no overlapping between local- and city-scale points of origin/destination.

We also observed the patterning of convergences of Integration scales in relation to distributions of relative deprivation or vulnerability. We found a degree of correlation in the two case-study contexts of Liverpool and Medellín. In Liverpool, high-deprivation areas tend to converge Integration scales, while in Medellín low-vulnerability areas tend to converge these scales. Discounting these indicators of socio-economic status, the convergences seem to relate more to urban morphologies based on dense, rectilinear structures. Areas bearing sparse, non-linear structures such as those typi- 
cally found at the urban peripheries tend to have singular, dominant Integration scale. These perhaps represent 'islands' of communities that are segregated in terms of relative deprivation or vulnerability. We draw a hypothesis from this study that movement infrastructures bear highly variegated significance for social inclusion, depending on the communities' specific constitution and circumstances. A follow-up study is required to test this hypothesis, where the investigators can analyse the participants' text descriptions presented by the workshop participants. This will form our next stage of work.

\section{Acknowledgements}

The research described in this article was supported by a Leverhulme Trust Research Grant RPG-2014-169. The authors are grateful to participants, education providers and local officers at the study sites, and to Placed Education $\mathrm{CIC}$ for assistance with facilitation in the Liverpool study. In the Medellín study, we would like to acknowledge the collaboration of the library public system and the youth organization Red de Personeros y Lideres estudiantiles de Belén, who actively contributed in the design and implementation of the workshops. Specially the staff of the libraries Parque Biblioteca Prebístero Jose Luis Arroyave San Javier and Parque Biblioteca de Belén, who also facilitated the installations and access to the local network of schools. We are also grateful to Prof Laura Vaughan, Bartlett School of Architecture, UCL, for her advice about the morphology sampling technique applied to this study. The work described here is entirely the authors' responsibility.

\section{Conflict of Interests}

The authors declare no conflict of interests.

\section{References}

Anciaes, P., Boniface, S., Dhanani, A., Mindell, J., \& Groce, N. (2016). Urban transport and community severance: Linking research and policy to link people and places. Journal and Transport \& Health, 3, 268-277.

Batty, M. (2013). The new science of cities. Cambridge, MA: MIT Press.

Brand, P., \& Dávila, J. (2011). Mobility innovation at the urban margins. City, 15(6), 647-661.

Chambers, R. (1997). Whose reality counts? Putting the first last. London: Intermediate Technology Publications.

DCLG. (2015). English indices of deprivation 2015. London: Department of Communities and Local Government.

Debertin, D., \& Goetz, S. (2013). Social capital formation in rural, urban and suburban communities. Staff $P a-$ per 474. University of Kentucky.

Drummond, H., Dizgun, J., \& Keeling, D. J. (2012). Medellín: A city reborn? Focus on Geography, 55, 146-154.
Gans, H. (2002), The sociology of space: A use-centered view. Cities \& Communities, 1(4), 329-340.

Gans, H. (2006), Jane Jacobs: Toward an understanding of "Death and Life of Great American Cities". Cities \& Communities, 5(3), 213-215.

Grannis, R. (1998). The importance of trivial streets: Residential streets and residential segregation. American Journal of Sociology, 103(6), 1530-1564.

Grannis, R. (2009), From the ground up: Translating geography into community through neighbor networks. Princeton, NY: Princeton University Press.

Gwyther, G. (2005). Paradise planned: Community formation and the master planned estate. Urban Policy and Research, 23(1), 57-72.

Hanley, L. (2017). Estates: An intimate history. London: Granta Books.

Hillier, B., \& Hanson, J. (1984). The social logic of space. Cambridge: Cambridge University Press.

Hillier, B., \& lida, S. (2005). Network and psychological effects in urban movement. In A. G. Cohn \& D. M. Mark (Eds.), Proceedings of spatial information theory: international conference, COSIT 2005, Ellicottsville, NY.

Hillier, B. (2007). Space is the machine. Cambridge: Cambridge University Press.

Hillier, B., \& Vaughan, L. (2007). The city as one thing. Progress in Planning, 67(3), 205-230.

Hylton, F. (2007). Medellín's makeover. New Left Review, 44.

Leeming, C. (2013). Why selling off homes for just $f 1$ in a derelict area of Liverpool makes sense. The Guardian. Retrieved from https://www.theguardian.com/com mentisfree/2013/feb/20/selling-homes-liverpool

Liverpool City Council (2013). Liverpool Economic Briefing 2013: A monitor of jobs, business and economic growth. Liverpool: Liverpool City Council.

Liverpool City Council. (2015). The index of multiple deprivation 2015: A Liverpool analysis. Liverpool: Liverpool City Council.

Liverpool City Council. (2016). The city of Liverpool key statistics bulletin (Issue 24, June 2016 Update). Liverpool: Liverpool City Council.

Logan, J. (2012) Making a place for space: Spatial thinking in social science. Annual Review of Sociology, 38, 507-524.

Lupton, R. (2003). "Neighbourhood effects": Can we measure them and does it matter? (CASE paper no. 73). London: Centre for Analysis of Social Exclusion, London School of Economics and Political Science.

McKenzie, L. (2015). Getting by: Estates, class and culture in austerity Britain. Bristol: Policy Press.

Medellín Cómo Vamos. (2016a). Informe de calidad de vida de Medellín, 2016: Desigualdad, pobreza y demografía. Medellín, Colombia: Medellín Cómo Vamos.

Medellín Cómo Vamos. (2016b). Encuesta de percepción ciudadana, Medellín 2016: Pobreza y desigualdad. Medellín, Colombia: Medellín Cómo Vamos.

Miller, B. (1992). Collective action and rational choice: 
Place, community, and the limits to individual selfinterest. Economic Geography, 68(1), 22-42.

O'Brien, J., \& Griffiths, S. (2017). Relating urban morphologies to movement potentials over time: A diachronic study with Space Syntax of Liverpool, UK. In Proceedings of the 11th Space Syntax Symposium. Lisbon: Instituto Superior Técnico.

O'Brien, J., \& Psarra, S. (2015). The dialogic city: Towards a synthesis of physical and conceptual artefacts in urban community configurations. In Proceedings of the Tenth International Space Syntax Symposium. London, UK.

O'Brien, J., Serra, M., Hudson-Smith, A., Psarra, S., Hunter, A., \& Zaltz Austwick, M. (2016), Ensuring VGI credibility in urban-community data generation: A methodological research design. Urban Planning, 1(2), 88-100.

Palaiologou, F., \& Vaughan, L. (2012). Urban rhythms: Historic housing evolution and socio-spatial boundaries. In Proceedings: Eighth International Space Syntax Symposium, Santiago de Chile.

Power, A. (2007). City survivors: Bringing up children in disadvantaged neighbourhoods. Bristol: Policy Press. Robinson, J. (2016). Comparative urbanism: New geographies and cultures of theorizing the urban. International Journal of Urban and Regional Research, 40, 187-199.

Sampson, R., Morenoff, J., \& Gannon-Rowley, T. (2002). Assessing "neighborhood effects": Social processes and new directions in research. Annual Review of Sociology, 28, 443-478.

Sibley, D. (1995). Geographies of exclusion: Society and difference in the west. Abingdon: Routledge.

SISBEN. (2015). Resultados sistema de identificación de potenciales beneficiarios de programas sociales 2015. Bogotá: Departamento Nacional de Planeación.

Sykes, O., Brown, J., Cocks, M., Shaw, D. \& Couch, S. (2013). A city profile of Liverpool. Cities, 35, 299-318.

UNESCO. (2002). Growing up in an urbanizing world. Paris: United Nations Education, Scientific and Cultural Organization.

Urry, J. (2002). Global complexity. Cambridge: Blackwell Publishing.

\section{About the Authors}

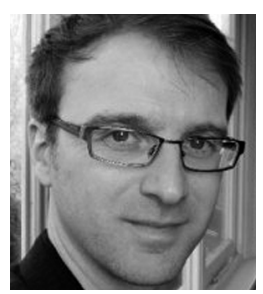

Jamie O'Brien is Senior Research Associate at the Centre for Advanced Spatial Analysis, University College London. His research relates methods for understanding urban communities' relationship with local spaces and spatial structures. Jamie has a background in visual arts and holds Doctor of Engineering from UCL in VR applications. He has received the award of Enterprise Scholar at the London Business School/UCL Centre for Scientific Enterprise.

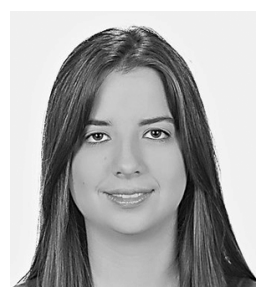

Laura García Vélez is an Environmental Engineer and gained MSc in Geographic Information Science relating to territorial planning. Since 2013, Laura has been involved in assisting research and consultancy projects in relation with urban planning and environmental management (Colombia and UK) and remote sensing for food security (The Netherlands and Ethiopia).

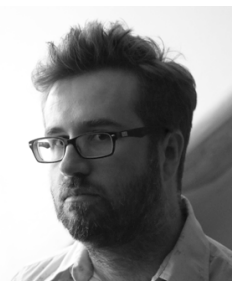

Martin Zaltz Austwick was Senior Lecturer at UCL in data visualization and programming (he has since left UCL). He has published work based on network analyses of bicycle flows in cities across the world, and is interested in the use of GPS to map walking routes through London, literary geographies and the science of cities. 


\section{Appendix}

\section{Explanation of the Index SISBEN and Its Manipulation for the Research}

According to the Alcaldía Mayor de Bogotá D.C. (2015) the SISBEN is a system to identify potential beneficiaries of social programs subsidized by the government of Colombia. For this purpose, each year a survey is applied under request to the citizens that want to apply to these benefits. In the case of Medellín, 1,676.622 people at the urban perimeter of Medellín took the survey during 2015 , which represents the $76 \%$ of the estimated total population for the city by the National Department of Statistics (DANE, 2009).

The results of the SISBEN survey, which inquires for diverse variables (examples: housing conditions, level of education, access to health, incomes, etcetera), allows to classify the population between a score of 0 and 100 (the lowest, the most vulnerable population) (Alcaldía Mayor de Bogotá D.C., 2015). In order to allocate the subsidizes, each social organization defines specific thresholds. For example, the Ministry of Social Protection (Resolución 3778 de 2012) gives subsidizes to the inhabitants that have a SISBEN score below 54.86 .

In the analysis of the urban morphologies in relation to the results of the SISBEN survey, the main challenge encountered is that there is not any index associated to specific geographical entities. On the other hand, the dataset consists on the amount of people that took the survey per neighbourhood and its associated scores classified in 10 ranges.

\section{Index Proposed Using the SISBEN Information}

For this reason, it was proposed to classify the geographical entities according to the amount of population in each neighbourhood that obtained SISBEN scores below 54.86 (threshold defined by the Ministry of Social Protection) and calculate its percentage in relation with the total amount of population within this score in the city.

\section{Why the Selection of SISBEN Dataset}

Other sources of population vulnerability are i) the survey of the quality of life realized each year by the municipality (Encuesta Calidad de Vida, ECV) and ii) the socioeconomical classification of the population according to the housing conditions (SEC). The reasons to select the SISBEN survey above these datasets are i) its higher spatial resolution (ECV is only calculated for the comuna level, 16 entities in Medellín), ii) its free availability, and iii) the consideration of other variables besides physical ones to classify the vulnerability of population.

\section{References}

Alcaldía Mayor de Bogotá D.C. (2015). Caracterización socioeconómica de la población encuestada con la metodología del Sisben III en Bogotá D.C. Enero de 2010 a Mayo de 2015. Retrieved from http://www.sdp.gov.co

DANE (2009). Municipio de Medellín, Proyecciones de Poblacion 2006-2015. Retrieved from https://www.medellin.gov.co 